\section{Emergency wheel}

Heritage Preservation's Emergency Response and Salvage Wheel is available as a free app for iPhones, iPods, and iPads. The app covers important issues to consider during the critical initial stages of an emergency that threatens cultural property, including "Disaster Alert," "Safety First," "Going Off-Site," "Stabilization," "Documentation," "Retrieve/Protect," "Assess Damage," "Salvage Priorities," and "Building Tips." It also outlines the first steps to be taken to salvage damaged books and paper, photographs, electronic records, paintings, textiles, furniture, ceramics/stone/metal, organic materials, and natural history specimens.

The app is available free-of-charge from the Apple App Store. Search for "ERS: Emergency Response and Salvage." It requires iOS 5.1 or later.

\section{Education directory}

The Preservation and Reformatting Section of the Association for Library Collections and Technical Services has updated its Preservation Education Directory. The 9th edition of the online directory contains course listings and content information for graduate-level preservation and preservation-related courses offered in the United States and Canada. It also lists institutions and organizations that provide continuing education courses in preservation. In this revision the directory has been expanded to cover audiovisual and digital media preservation.

The directory is available free-of-charge at www.ala.org/alcts/resources/preservation /educationdirectory.

\section{Preserving e-resources}

The Coalition for Networked Information (CNI) has mounted video of "Preservation Status of e-Resources: A Potential Crisis in

Jane Hedberg is senior preservation program officer at Harvard University Library, e-mail: jane_hedberg@ harvard.edu; fax: (617) 496-8344
Electronic Journal Preservation.” The lecture was delivered at the December 2011 CNI meeting by Oya Rieger, associate university librarian for digital scholarship services at Cornell University, and Robert Wolven, associate university librarian for bibliographic services and collection development at Columbia University. The speakers reported some early findings from their study of ejournal preservation that indicate significant preservation risks remain despite recent efforts to mitigate them.

The video is available free-of charge on YouTube at http://youtu.be/sjAaSRJILd0 and on Vimeo at http://vimeo.com/35776220.

\section{Orphan works conference}

The Berkeley Center for Law and Technology at University of California-Berkeley School of Law has mounted audio recordings and slide shows from many of the presentations made at "Orphan Works and Mass Digitization: Obstacles and Opportunities." The conference, held on April 12-13, 2012, in Berkeley, California, considered the current relationship between copyright law and orphan works (i.e., works still under copyright but whose rights holders cannot be located through a reasonably diligent search).

Session 1 was "Who wants to make use of orphan works and why?", session 2 was "Who is concerned about broader access to orphans and why?," session 3 was "What is the best approach to addressing the orphan works problem?," session 4 was "What role should registries play in averting orphan work problems? What mechanisms will facilitate information sharing about which works are public domain, orphan, or open access?," session 5 was "Who wants to do mass digitization and why?," and session 6 was "Should data mining and other non-consumptive uses of in-copyright digital works be permissible, and why?"

The agenda, recordings, and slide shows are available free-of-charge at www.law. berkeley.edu/11731.htm. $\boldsymbol{n}$ 